\title{
Congenital retinal dystrophies: a study of early cognitive and visual development
}

\author{
Marilyn M Black, Patricia M Sonksen
}

\begin{abstract}
The reported incidence of mental retardation in Leber's congenital amaurosis has varied from $10 \%$ to $87 \%$. There has been no review of the estimate since it became possible to delineate an increasing number of diagnostic subcategories. In this study, the visual and cognitive development of 38 children with congenital retinal dystrophies has been followed up prospectively. Children with associated disorders in other systems and those with central nervous system malformations or degenerations were significantly more likely to have learning disability than those without additional medical problems. Most subgroups made little or no visual progress with the exception of the group with associated hypoplasia of the cerebellar vermis. The study highlights the importance of using the specialised techniques now available to delineate fully the visual diagnosis and paediatric perspective because of their relevance to congitive and visual prognosis.
\end{abstract}

The congenital retinal dystrophies (CRDs) are a group of rare disorders in which severe visual impairment from early infancy results from dysfunction of retinal receptors. The electroretinogram is characteristically absent or severely attenuated; visual evoked responses are usually reduced. The appearance of the retina is normal or near normal in early childhood, differentiating these conditions from the retinal dysplasias, although degenerative or pigmentary changes may occur later. All these dystrophies are hereditary, most being autosomal recessive.

The first of these conditions to be described, in 1869 , was Leber's congenital amaurosis, ${ }^{1}$ and until recently this has remained the 'umbrella' diagnosis given to patients with CRD. However, with increasing recognition of the heterogeneity of these disorders, ${ }^{2-4}$ several genetically distinct subtypes of Leber's amaurosis and an infantile onset form of retinitis pigmentosa have been delineated. ${ }^{2-6}$ It has also been recognised that retinal dystrophy can be associated with brain malformation as in Joubert's syndrome ${ }^{7}$ or may be a presenting feature of neurndegenerative disorders such as Zellweger's disease. ${ }^{2} 89$ Precise diagnosis can still be difficult at presentation, and an initial label of Leber's amaurosis may need revision. ${ }^{2}$

This heterogeneity makes it difficult to interpret previous reports of the incidence of severe learning disability in Leber's amaurosis which vary from $10 \%$ to $87 \% .^{3410}{ }^{11}$ It is possible that some of the retarded children described in these studies would today be more precisely categorised.

The present study was undertaken to examine cognitive and visual progress in the first five years of life in the congenital retinal dystrophies, within and between diagnostic subgroups.

\section{Methods}

SUBJECTS

Four hundred severely visually impaired children attended the Developmental Vision Clinic at the Wolfson Centre between 1972 and 1989. Forty two fulfilled the definition of congenital retinal dystrophy described in the introduction and were aged less than 5 years when first seen Four aged less than 12 months at last assessment were excluded because judgments on verbal development would have been inappropriate. The remaining 38 children form the study population.

All the children had full ophthalmological examination and investigation, including electrophysiological studies, in the department of ophthalmology at the Hospital for Sick Children, Great Ormond Street. Other investigations, including computed tomography brain scans and metabolic studies, were performed where appropriate in the departments of neurology and metabolic diseases. An umbrella diagnosis of Leber's amaurosis given earlier was refined in eight children as a result of follow up investigations. Revised diagnoses were used in this study.

The 38 children were allocated to four groups according to the nature of the retinal dystrophy and the presence and nature of other medical problems or disabilities (table 1). The children in groups III and IV all had central nervous system malformation or degeneration. Groups I (Leber's congenital amaurosis) and II ('other' congenital retinal dystrophies) were subdivided into those with and without additional chronic medical problems or disabilities. As the aim of the study was to explore development within

Table 1 Distribution according to diagnostic category

\begin{tabular}{lll}
\hline Diagnostic category & $\begin{array}{l}\text { No of } \\
\text { children }\end{array}$ \\
\hline I & $\begin{array}{l}\text { Leber's congenital amaurosis } \\
\text { Ia No medical problems }(\mathrm{n}=13)\end{array}$ & 20 \\
& Ib With medical problems $(\mathbf{n}=7)$ & \\
II $\quad$ 'Other' congenital retinal dystrophies & 6 \\
& IIa No medical problems $(\mathrm{n}=3)$ \\
III & IIb With medical problems (n=3) & \\
IV & CRD with cerebellar vermis hypoplasia & 7 \\
Total & CRD with neurodegenerative disorder & 5 \\
\end{tabular}

CRD, congenital retinal dystrophy. 
and between diagnostic categories, the level of intellectual function was not taken into account in allocation. Groups II, III, and IV all contained children in whom an initial label of Leber's amaurosis had been revised.

None of the 13 children with Leber's amaurosis in group Ia had any additional medical or sensory problems. The seven children in group Ib had well recognised associations of Leber's amaurosis: three had sensorineural deafness, two had impaired renal concentrating ability, one had small renal cysts (renal function was otherwise normal in all three), and one had cardiomyopathy.

The visual diagnosis in the three children without additional medical problems in group IIa was congenital cone dysfunction. In group IIb the additional medical problem was epilepsy in one child with congenital stationary night blindness, deafness in one of the two children with infantile onset retinitis pigmentosa, and hypotonia with motor delay in the other.

Five of the seven group III children with cerebellar vermis hypoplasia had presented with the abnormal breathing patterns in infancy of classical Joubert's syndrome. All seven had motor disability with hypotonia and ataxia, six had saccade palsy, and one developed renal failure due to nephronophthisis at the age of 5 years.

The diagnosis in two of the five children in group IV in whom CRD was part of a neurodegenerative disorder was Zellweger's syndrome. A specific diagnosis was not possible in the other three despite extensive investigation. All had multiple additional disabilities. Motor disability presented as hypotonia in four children and choreoathetosis in one. The two with Zellweger's syndrome were also deaf and had abnormal liver function. One of the others was deaf and progressive cerebellar atrophy was documented in another.

Only four children had experienced adverse perinatal events: two were premature, one in group Ib and one in group III; one in group III had duodenal atresia and one in group IIb had hyperbilirubinaemia requiring exchange transfusion.

\section{PROCEDURES}

Children are seen at each visit to the clinic by a developmental paediatrician, psychologist, and specialist health visitor experienced in the assessment and management of babies and young children with severe visual disability. A speech therapist, occupational therapist, and physiotherapist are involved as appropriate. Assessment findings are developed into programmes to promote many aspects of cognitive and motor skill and visual development. ${ }^{12-14}$ Babies are reassessed and their programmes updated every four months during the first year, every six months during the second, and annually thereafter. Development is monitored at each visit by the psychologist or developmental paediatrician on the Reynell-Zinkin scales for young visually handicapped children. ${ }^{15}$ These scales provide an age level of function rather than a quotient, with standards for blind, partially sighted, and sighted children. The distinction between blind/very severely visually impaired (VSVI), and partially sighted/moderately severely visually impaired (MSVI) was made according to criteria given below.

Progress was monitored on the three most intellectually loaded subscales: response to sound and verbal comprehension, expressive language (structure), and sensorimotor understanding. The standard appropriate to a child's degree of visual impairment was used to designate development as normal or delayed. Children falling on or above the standard were designated normal and those falling below as delayed for that scale of development.

Vision was assessed at each visit by a method appropriate to the child's developmental stage; either a series of solid round objects graded in size from a $12.5 \mathrm{~cm}$ ball to $1 \mathrm{~mm}$ cake decoration known as 'hundreds and thousands'; or standard Snellen optotypes. All the children were severely visually impaired. The degree of visual impairment was classified as very severe (VSVI) if a child was unable to see a $2.5 \mathrm{~cm}$ cube at $30 \mathrm{~cm}$ or had a best corrected acuity of less than 1/60; and as moderately severe (MSVI) at levels better than this.

The degree of visual impairment was very severe in nine of the 13 with uncomplicated Leber's amaurosis (group Ia); in five of the seven children with Leber's amaurosis and other medical problems (group Ib); in none of the three children with cone dystrophy (group IIa); in one of the three with 'other' CRDs and medical problems (group IIb); in three of the seven with cerebellar vermis hypoplasia (group III); and in four of the five children with neurodegenerative dis̀orders (group IV).

\section{Results}

There was no significant difference between diagnostic groups in age at first attendance or length of follow up. The sexes were evenly distributed except in group II, where five of the six were boys.

\section{COGNITIVE PROGRESS}

Table 2 summaries the results for cognitive development within each diagnostic subgroup. Twenty three $(61 \%)$ of the children were developmentally delayed on one or more of the Reynell-Zinkin subscales. The distribution and pattern within each diagnostic group is first described.

\section{Group Ia}

Ten children $(77 \%)$ performed at or above the relevant standard in all three subscales of the Reynell-Zinkin scales. Three (23\%) were delayed in one or more fields; one in all three fields (see table 3); one in sensorimotor understanding; and one in expressive language. There was no difference between the non-delayed and delayed patients according to sex distribution $(5 / 10$ and $2 / 3$ boys) or degree of visual impairment $(7 / 10$ and $2 / 3$ VSVI). The incidence of developmental delay in this group is similar to that found in 
severely visually impaired children whatever the cause. ${ }^{10} 1216$

\section{Group $I b$}

Only one child in this subgroup, the child with renal cysts, performed above the relevant standard in all three fields of development. The remaining six $(86 \%)$ were delayed, five in all fields and one in expressive language and sensorimotor understanding.

\section{Group IIa}

All three children with congenital cone dysfunction progressed normally in all three fields of development.

\section{Group IIb}

The child with infantile retinitis pigmentosa and motor delay made normal intellectual progress; the other two children were delayed in all three fields.

\section{Group III}

All seven children were delayed in at least one field. Three were severely globally retarded and the other four all had severe oral dyspraxia with severe delay in expressive language. Three of the latter were moderately delayed in other fields though one achieved normal scores in

Table 2 Developmental progress by diagnostic category. Results are number (\%)

\begin{tabular}{llll}
\hline \multicolumn{2}{l}{ Diagnostic category } & No delay & Delay \\
\hline Ia & Leber's-no other problems & $10(77)$ & $3(23)$ \\
Ib & Leber's-with other problems & $1(14)$ & $6(86)$ \\
IIa & 'Other' CRDs-no other problems & $1(100)$ & $0(0)$ \\
IIb & Other' CRDs-with other problems & $1(33)$ & $2(67)$ \\
III & CRD with cerebellar vermis hypoplasia & $0(0)$ & $7(100)$ \\
IV & CRD with neurodegenerative disorder & $0(0)$ & $5(100)$ \\
\hline
\end{tabular}

CRD, congenital retinal dystrophy.

Table 3 Clinical details of four children showing deceleration or regression of development

\begin{tabular}{|c|c|c|}
\hline Medical perspective & $\begin{array}{l}\text { Developmental and } \\
\text { behavioural changes }\end{array}$ & Other factors \\
\hline $\begin{array}{l}\text { Uncomplicated Leber's } \\
\text { amaurosis (Ia) }\end{array}$ & $\begin{array}{l}\text { Deceleration and behavioural } \\
\text { changes with 'autistic' } \\
\text { features in second year }\end{array}$ & - \\
\hline $\begin{array}{l}\text { Leber's amaurosis with } \\
\text { impaired renal } \\
\text { concentration (Ib) }\end{array}$ & $\begin{array}{l}\text { Deceleration and behavioural } \\
\text { changes with 'autistic' } \\
\text { features in second year; } \\
\text { regression in third year; } \\
\text { unexpected death age } 3.5 \text { years }\end{array}$ & $\begin{array}{l}\text { Family prolems during } \\
\text { second year }\end{array}$ \\
\hline $\begin{array}{l}\text { Leber's amaurosis with } \\
\text { impaired renal } \\
\text { concentration (Ib) }\end{array}$ & $\begin{array}{l}\text { Deceleration and disorder of } \\
\text { language development in } \\
\text { third year }\end{array}$ & - \\
\hline $\begin{array}{l}\text { Congenital stationary } \\
\text { night blindness (IIb) }\end{array}$ & $\begin{array}{l}\text { Deceleration in third year. } \\
\text { Epilepsy+attention deficit } \\
\text { disorder in fourth year }\end{array}$ & Neonatal jaundice \\
\hline
\end{tabular}

Table 4 Visual progress by diagnostic category

\begin{tabular}{llllllll}
\hline Diagnostic group & \multicolumn{2}{l}{ Visual function } & & \multicolumn{2}{c}{ Final visual level } \\
\cline { 2 - 3 } & No change & Better & Worse & & VSVI & MSVI \\
\hline I Leber's amaurosis & 19 & 0 & 1 & & 14 & 6 \\
II 'Other' CRDs & 6 & 0 & 0 & 1 & 5 \\
III CRD with cerebellar vermis hypoplasia & 2 & 5 & 0 & & 6 \\
IV CRD with neurodegenerative disorders & 4 & 1 & 0 & & 3 & 2
\end{tabular}

CRD, congenital retinal dystrophy; VSVI, MSVI, very severe and moderately severe visual impairment. sensorimotor understanding and verbal comprehension.

Group IV

All five children were severaly globally retarded.

Clear differences in the distribution of learning disability were seen between diagnostic categories; their significance was determined using the Fisher exact probability test. Children without chronic medical problems or sensory or motor disability (groups Ia and IIa) were significantly less likely to be delayed than those with such problems (group Ib, IIb, III, and IV): $3 / 16$ and $20 / 22$ respectively $(p<0.001)$. The difference remained significant when those with documented central nervous system malformation or degeneration (groups III and IV) were excluded: $3 / 16$ children in groups Ia and IIa were delayed compared with $8 / 10$ in groups Ib and IIb $(p<0.01)$. Even within the group with Leber's amaurosis the difference between those with and those without other medical problems reached significance: $6 / 7$ children in group Ib were delayed compared with $3 / 13$ in group Ia $(\mathrm{p}<0.025)$

Four of the 38 children showed slowing or regression of development during the first 12 to 18 months. The slowing was accompanied by the appearance of some autistic features in two children. Clinical information is summarised in table 3.

\section{VISUAL PROGRESS}

The visual level in the majority of children in groups I, II, and IV did not change during the period of study (table 4). Vision deteriorated in one child in group I who developed traumatic cataracts as a result of eye poking. In contrast, the visual level in the majority of group III improved, in two from very severe to moderately severe impairment and in two from moderately severe to mild; improvement has not been maintained in two of these patients who have both shown deterioration in visual acuity in later childhood.

\section{Discussion}

The study clearly shows that impaired intellectual potential and/or specific learning disability are more common when congenital retinal dystrophy is associated with additional medical problems. The influence of central nervous system malformation or degeneration and of dual sensory disability on a child's potential for mental development is expected. The poorer developmental prognosis of children with medical problems in other systems needs further consideration. Only one child in the series, the child with Leber's amaurosis and cardiomyopathy, had significant ill health during the study period; she remained moderately delayed even after successful treatment of her cardiac failure. With the exception of some of the neurodegenerative disorders, the enzymatic abnormalities in the congenital retinal dystrophies have yet to be identified. ${ }^{5}$ The presence of disorder outside the visual system may reflect a more widespread disturbance of cellular func- 
tion, expressed in some as intellectual impairment.

Lack of vision imposes major constraints on many aspects of development. ${ }^{12}$ Parents are best able to implement a programme of developmental intervention ${ }^{13}$ when content and confident of the future. ${ }^{17}$ Uncertainty about developmental potential is likely to heighten parental anxiety and jeopardise development of a baby further. The finding that babies without, as opposed to with, additional medical problems are more likely to have good developmental potential strengthens the basis for developmental counselling about this group of conditions. Lessening the uncertainties surrounding a baby's future is likely to enable parents to play a more active part in promoting development.

Visual prognosis also differed among the subgroups. Except in children with Joubert's syndrome it was uniformly poor. This finding is supported by a study which evaluated a programme to promote cognitive, motor, and visual development in 58 babies with a variety of visual disorders; all five children with Leber's amaurosis failed to make visual progress whereas both children with Joubert's syndrome made progress. ${ }^{14}$ Better preservation of visual evoked responses in the latter subgroup of CRD may have relevance. ${ }^{2}$ Fielder, Fulton, and Mayer, however, recently reported significant visual improvement in three of five babies with Leber's amaurosis. ${ }^{18}$

Behavioural changes including autistic features appeared after a period of normal development in only two of the 20 children with Leber's amaurosis. In both this occurred during the second year in parallel with deceleration of development. Rogers and Newhart-Larson ${ }^{19}$ using the Childhood Autism Rating Scale ${ }^{20}$ and the Autism Behaviour Checklist ${ }^{21}$ demonstrated significantly more characteristics of autism in five older boys with Leber's amaurosis than in five others who were congenitally blind from other causes. The appearance of autistic features was not associated with developmental deceleration in their cases; in the two children in this study it was associated with the development of a cognitive disorder and in this respect resembles more a pervasive disintegrative disorder. ${ }^{22}$ In another study of 14 preschool cogenitally blind children, attending the DVC, deceleration occurred in two of eight with Norrie's disease and two of six with blindness due to other causes, such as anophthalmos, buphthalmos, and optic disc hypoplasia. This was accompanied by behaviour changes and some autistic features in two of the four. ${ }^{16}$

Our experience suggests that the onset of developmental and behavioural disorder in the second and third year of life is not disorder specific but found in a variety of conditions causing congenital blindness. It may be that the central nervous system is particularly vulnerable to the effects of blindness during the second year of life or to a combination of this plus adverse social/emotional stresses-the latter being documented in at least $50 \%$ of our cases of deceleration. Alternatively, cellular dysgenesis of variable degree within the central nervous system may be a feature of many of the conditions responsible for congenital blindness. Evidence that this is correct is growing-for example, in CHARGE association, Joubert's syndrome, and in septo-optic dysplasia. ${ }^{23-25}$

Our findings support the recommendations of Lambert et al that the presence of abnormal neurological signs or developmental delay in a child thought to have Leber's amaurosis should prompt full visual, neurological, and paediatric overview. ${ }^{2}$ We would add that the finding of additional medical problems in a child with CRD is cause for caution and conversely their absence a cause for optism when counselling for developmental prognosis.

1 Leber T. Ueber retinitis pigmentosa und angeborene amaurose. Graefes Arch Clin Exp Ophthalmol 1869;15:1-25. Lambert SR, Kriss A, Taylor D, Coffey R, Pembrey M. Follow-up and diagnostic reappraisal of 75 patients with Leber's congenital amaurosis. Am $\mathcal{F}$ Ophthalmol 1989;107:

3 Vaizey MJ, Sanders MD, Wybar KC, Wilson J. Neurological abnormalities in congenital amaurosis of Leber. Arch Dis abnormalities in congen

4 Schroeder R, Mets MB, Maumenee IH. Leber's congenital amaurosis; retrospective review of 43 cases and a new fundus finding in 2 cases. Arch Ophthalmol 1987;105: 356-9.

5 Russell-Eggitt IM, Taylor DSI, Clayton PT, Garner A, Kriss A, Taylor JFN. Leber's congenital amaurosis: a new syndrome with a cardiomyopathy. Br F Ophthalmol 1989; 73:250-4.

6 Senior B, Friedmann AI, Brando JL. Juvenile familial nephropathy with tapeto-retinal degeneration; a new occulorenal dystrophy. Am $\mathcal{F}$ Ophthalmol 1961;52:625-33.

7 King MD, Dudgeon J, Stephenson JBP. Joubert's syndrome with retinal dysplasia: neonatal tachypnoea as the clue to a genetic brain-eye malformation. Arch Dis Child 1984;59:

8 Garner A, Fielder AR, Primavesi R, Stevens A. Tapetoretinal degeneration in the cerebro-hepato-renal (Zellweger's) degeneration in the cerebro-hepato-re

9 Weleber RG, Tongue AC, Kennaway NG, Budden SS, Buist NRM. Ophthalmic manifestations of infantile phytanic acid storage disease. Arch Ophthalmol 1987;102:1317.

10 Nickel B, Hoyt CS. Leber's congenital amaurosis. Is mental retardation a frequent associated defect? Arch Ophthalmol 1982;100:1089-92.

11 Dekalan AS. Mental retardation and neurological involvement in patients with congenital retinal blindness. Dev Med Child Neurol 1972;14:436-44.

12 Sonksen PM, Levitt S, Kitzinger $M$. Identification of constraints acting on motor development in young visually disabled children and principles of remediation. Child Care Health Dev 1984;10:274-86.

13 Sonksen PM, Stiff B. Show me what my friends can see. London: The Wolfson Centre, 1991.

14 Sonksen PM, Petrie A, Drew KJ. Promotion of visual development of severely visually impaired babies: evaluation of a developmentally based programme. Dev Med Child Neurol 1991;33:320-35.

15 Reynell J, Zinkin P. Manual for Reynell-Zinkin scales. Windsor: National Foundation of Education Research, Windsor:

16 Goodyear HM, Sonksen PM, McConachie H. Norrie's disease: a prospective study of development. Arch Dis Child 1989;64:1587-92.

17 Sonksen PM. Constraints upon parenting: experience of a paediatrician. Child Care Health Dev 1989;15:29-36.

18 Fielder AR, Fulton AB, Mayer DL. Visual development of infants with severe occular disorders. Ophthalmology 1991; 98:1306-9.

19 Rogers SJ, Newhart-Larson S. Characteristics of infantile autism in five children with Leber's congenital amaurosis. Dev Med Child Neurol 1989;31:598-608.

20 Schopler E, Reichler R, De Villis R, Daly K. Toward an objective classification of childhood autism: childhood autism rating scale (CARS). 7 Autism Dev Disord 1980;10: 91-103.

21 Krug D, Arick J, Almond P. Behaviour checklist for identifying severely handicapped individuals with high levels of autistic behaviour. $\mathcal{f}$ Child Psychol Psychiatry levels of autis

22 Burd L, Fisher $\mathbb{W}$, Kerbeshian J. Childhood onset pervasive development disorder, dementia infantalis or disintegrative psychosis. I Child Psychol Psychiatry 1988;29:155-63.

23 Lin AE, Siebert JR, Graham JM. Central nervous system malformations in the CHARGE association. Am $\mathcal{f}$ Med Genet 1990;37:304-10.

24 Cantani A, Lucenti P, Ronzani GA, Santoro C. Joubert's syndrome; review of the fifty-three cases so far published. Ann Genet (Paris) 1990;33(2):96-8.

25 Roberts-Harry J, Green SH, Willshaw HE. Optic nerve hypoplasia: associations and management. Arch Dis Child 1990;65:103-6. 